\title{
Impact of preconception health education on health locus of control and self-efficacy in women
}

F. Bastani, ${ }^{1}$ S. Hashemi, ${ }^{2}$ N. Bastani ${ }^{3}$ and H. Haghani ${ }^{4}$

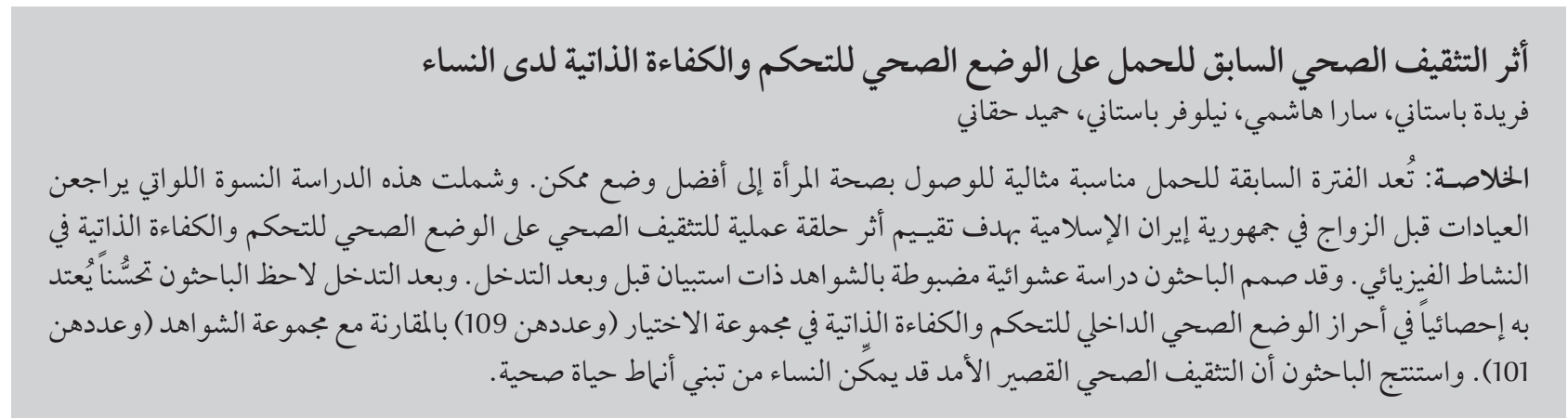

ABSTRACT The preconception period is an ideal opportunity to optimize women's health. This study of women attending premarital clinics in the Islamic Republic of Iran aimed to evaluate the impact of a health education workshop on their health locus of control and self-efficacy in physical activity. The design was a randomized controlled trial with a questionnaire before and after the intervention. At post-intervention, there were significant increases in scores of internal health locus of control and self-efficacy in the experimental group $(n=109)$ compared to the control group $(n=101)$. It was concluded that a short-term health education may empower women to adopt healthy lifestyles.

\section{Impact de l'éducation sanitaire avant la conception sur le lieu de contrôle de la santé et l'auto-efficacité chez les femmes}

RÉSUMÉ La période antérieure à la conception est un excellent moment pour améliorer la santé des femmes. Cette étude réalisée sur des femmes consultant dans des services prénuptiaux en République islamique d'Iran visait à évaluer l'impact d'un seminaire-atelier portant sur l'éducation sanitaire, sur le lieu de contrôle de la santé et l'auto-efficacité en termes d'activité physique. II s'agissait d'un essai randomisé contrôlé, comportant un questionnaire administré avant et après l'intervention. À l'issue du séminaire-atelier, les scores de contrôle interne du groupe expérimental $(\mathrm{n}=109)$ avaient beaucoup augmenté par rapport à ceux du groupe témoin $(\mathrm{n}=101)$. Nous en avons conclu qu'une éducation sanitaire de courte durée pouvait aider les femmes à adopter un mode de vie sain. 


\section{Introduction}

Effective interventions and health education programmes concerning healthy lifestyles are important for women of reproductive age. In the Islamic Republic of Iran there is a need for lifestyle education for women, especially at the preconception period, which as an ideal opportunity to optimize the health of the mother-to-be [1].

Understanding the psychosocial characteristics of individuals may be useful for identifying effective health interventions. In this study, health locus of control (HLOC) and self-efficacy were used as the framework for a health education programme. HLOC relates to the idea that individuals' perceived degree of control over their health is a determinant of their health behaviour [2]. People with a high internal HLOC believe that the outcome of their own health is related to their behaviour, for example in physical activity. A higher internal HLOC is a predictive factor for positive outcomes in health education interventions in the Islamic Republic of Iran and elsewhere [3-6]. Self-efficacy, a key construct of Bandura's social cognitive theory, represents how much people believe that they are competent to confront the challenges in their own health behaviour. Self-efficacy is a predictive variable of health behaviour in smoking cessation, weight loss, prevention of chronic diseases [7] and physical activity participation by women [8].

The main objective of the present study was to evaluate the impact of a health education intervention regarding exercise/physical activity among a group of Iranian women attending premarital counselling clinics (PMCs). In order to receive permission to marry in the Islamic Republic of Iran, all couples who intend to marry are required to attend a PMC for screening for genetic problems such as beta-thalassaemia and for drug abuse and to participate in a single session of a reproductive health programme (including topics such as family planning, HIV/AIDS, sexually transmitted infections).

\section{Methods}

\section{Design and study setting}

This randomized controlled trial with a prospective experimental design was carried out in Tehran, Islamic Republic of Iran between December 2006 and September 2007.

Comparisons were made of internal and external HLOC scores and exercise/physical activity self-efficacy scores before and after the intervention in an experimental and a control group of women.

The study setting was all PMCs in the west Tehran area. By the start of the study, 1 of the clinics was closed and so the study was conducted in the only 2 active, large PMCs in the area.

\section{Study sample}

A consecutive sample of Iranian women who were attending a PMC and met the inclusion criteria were recruited for the study. The sample size was estimated at 240 subjects (120 women in the intervention and control groups) based on the changes in self-efficacy in a related study [9] with consideration of $95 \%$ confidence level and power test of $80 \%$.

The inclusion criteria for women were as follows: of childbearing age (18-35 years); healthy with no identifiable health risk factors (self-reported); intending to conceive in their first year of marriage; and literate in Farsi. Women with any medical or health problems during the recruitment period were excluded.

Women who satisfied the inclusion criteria were invited to participate and received brief information about the study. All participants were volunteers and signed a written informed consent prior to taking part in the study. Ethical approval for the study was granted by the research committee of Iran University of Medical Sciences.

Women were randomized into 2 groups using a block randomization method [10], so that groups of women in different categories of age and education level were randomly assigned separately to the intervention or control group. This method enhances the likelihood of detecting differences between the groups [11].

\section{Data collection}

The major dependent variables (HLOC and physical exercise self-efficacy) were measured before and 2 weeks after the intervention. The rationale for selecting this pre-post intervention interval was based on a previous study of a health counselling intervention in the Islamic Republic of Iran [12].

Data were collected by questionnaires that included sociodemographic items as well as the HLOC and exercise self-efficacy scales. The study participants were asked to complete the questionnaires in a quiet room during their visit to the premarital counselling clinic. The pre-intervention questionnaires were completed before the routine marital counselling session. Two weeks after the health education programme, the post-intervention questionnaires were mailed to all the subjects' mailing address (home or workplace) with a prepaid envelope and they were asked to return their completed questionnaires to the principal researcher. Subjects who failed to return the filled questionnaire were contacted by telephone.

In this study, HLOC was assessed using the Multidimensional Health Locus of Control scale [13], the Farsi language version of which has been validated in previous Iranian studies $[14,15]$. This scale consists of 11 items, each of which is rated on a 6-point scale from strongly disagree to strongly agree, with adequate internal consistency; 5 items contribute to the internal locus of control scale (e.g. "People's ill health results from their 
own carelessness") and 6 items concern the external locus of control scale (e.g. "People who never get sick are just plain lucky"). Ratings are summed so that scores on internal items rangefrom 6-30, with higher scores indicating greater belief in internal HLOC, and scores on external items range from 6-36, with higher scores indicating greater belief in external HLOC. The self-efficacy of physical exercise was assessed using the Health-Specific Self-Efficacy Scale [16]. This scale has been previously tested for reliability and validity in Iranian studies $[17,18]$.

Before conducting the study, the scales were tested on 20 Iranian women to confirm their validity and ensure their clarity and understandability. To establish the internal consistency of the questionnaire, Cronbach alpha coefficients were calculated and found to be 0.86 for the HLOC scale, 0.77 for the physical exercise self-efficacy scale and 0.84 for the total questionnaire. The content validity of the scales was established by an extensive review by 10 faculty members qualified in obstetrics and gynaecology and women's health in the Department of Health in Iran University of Medical Sciences.

\section{Intervention}

The intervention was a preconception health education programme for the women in the experimental group. This took the form of a single 2-hour workshop session in which 8-12 women participated. Group education was selected for the intervention as it is an effective method for the topics covered by this intervention and it costs less than oneon-one teaching [19]. The workshops were scheduled at times convenient for the participants and took place in a quiet room in the PMC. The workshops were presented by the investigators who were qualified in health education and women's health.

The education was aimed at empowering women to understand the future risks of unhealthy lifestyles. The following topics were covered: introduction to healthy lifestyles and physical activity; the benefits of healthy lifestyles for physical, psychological and emotional health in women; the correlations of unhealthy and healthy lifestyles (including physical activity) with morbidity and mortality; and the consequences of overweight and/or underweight on pregnancy and pregnancy outcomes.

Each woman in the experimental group also attended an individualized face-to-face meeting 1 hour before the workshop to advise her about healthy lifestyles, with the focus on the benefits of physical activity, and also to address the participant's initial concerns and questions and to guide the participant in identifying key issues at the workshop.

Women in both the intervention and control groups received the routine clinic premarital sessions, but the women in the control group received no special healthy lifestyle training.

The initial sample size was 240 , with 120 women in each group who completed the pre-intervention questionnaires. A total of 30 women ( 11 in the experimental and 19 in the control group) did not complete the post-intervention questionnaires and their data were excluded from the analysis, giving a final sample size in the experimental and control groups of 109 and 101 women respectively. The background characteristics of the non-respondents were not statistically different from the respondents.

\section{Analysis}

The results were processed using SPSS for Windows, version 14.0. Data were mainly presented as means and standard deviation (SD). The independent and 2-tailed paired Student $t$-test were applied to estimate differences between and within groups. Data were entered twice into the SPSS data file. The difference between baseline and follow-up scores was compared using the $t$-test. Change scores, computed by subtracting the baseline scores from the follow-up scores, were used to assess differences between 2 groups, with $P$ $<0.05$ considered significant. All variables displayed a normal distribution using the Kolmogorov-Smirnov test.

\section{Results}

\section{Background characteristics}

The mean age of participants was 25.7 (SD 4.8) years: 25.2 (SD 4.4) years in the experimental group and 26.1 (SD 5.2 ) in the control group. No significant differences were found between the experimental and control groups regarding age, education level and economic status in the pre-intervention questionnaires (Table 1). Economic status was categorized as good, moderate or bad, based on the subjects' self-report.

\section{Pre- and post-intervention scores}

Table 2 shows the mean scores for the experimental and the control groups for internal and external HLOC and physical activity self-efficacy pre- and post-intervention. There were no significant differences between the 2 groups in terms of HLOC and exercise selfefficacy on the pre-intervention scores. However, post-intervention, there was a significant difference in scores between the experimental and control groups with respect to internal HLOC $(P<0.001)$, but no significant difference with respect to external HLOC $(P=0.890)$ (Table 2). Comparing the difference in mean scores pre- and post-intervention showed significant differences between the experimental and control groups for all the dependent variables (Table 3).

In addition correlation coefficients revealed no association between demographic variables and the main dependent variables HLOC and exercise self-efficacy (Table 1). 


\begin{tabular}{|c|c|c|c|c|c|c|c|}
\hline \multirow[t]{2}{*}{ Characteristic } & \multicolumn{2}{|c|}{$\begin{array}{l}\text { Experimental group } \\
\qquad(n=120)^{\mathrm{a}}\end{array}$} & \multicolumn{2}{|c|}{$\begin{array}{l}\text { Control group } \\
\qquad(n=120)^{\mathrm{a}}\end{array}$} & \multicolumn{2}{|c|}{$\begin{array}{c}\text { Total } \\
(n=240)^{\mathrm{a}}\end{array}$} & \multirow[t]{2}{*}{$\begin{array}{c}P \text {-value } \\
\text { (Fisher exact test) }\end{array}$} \\
\hline & No. & $\%$ & No. & $\%$ & No. & $\%$ & \\
\hline Age (years) & & & & & & & 0.07 \\
\hline $18-26$ & 78 & 65.0 & 63 & 52.5 & 141 & 58.8 & \\
\hline $27-35$ & 42 & 35.0 & 57 & 47.5 & 99 & 41.3 & \\
\hline Education level & & & & & & & 0.89 \\
\hline Diploma and below & 43 & 35.8 & 45 & 35.5 & 88 & 36.7 & \\
\hline University & 77 & 64.2 & 75 & 62.5 & 152 & 63.3 & \\
\hline Employment status & & & & & & & 0.42 \\
\hline Employed & 45 & 37.8 & 38 & 32.5 & 83 & 35.2 & \\
\hline Not employed & 74 & 62.2 & 79 & 67.5 & 153 & 64.8 & \\
\hline Economic status & & & & & & & 0.17 \\
\hline Good & 33 & 27.5 & 43 & 36.1 & 76 & 31.8 & \\
\hline Bad/moderate & 87 & 72.5 & 76 & 63.9 & 163 & 68.2 & \\
\hline
\end{tabular}

${ }^{a}$ Data were missing in some categories and 30 women did not complete the post-intervention questionnaires.

\section{Discussion}

Our study provides support for the positive effect of a short-term educational intervention on the psychological determinants of women's health and healthy lifestyles. The changes in the scores for external HLOC before and after the intervention were significant compared with those of the control group who received no lifestyle education. Our results suggest that the independent variable (health education intervention in the form of 1-day workshop) had a positive impact on psychological aspects of adopting healthy behaviours (HLOC and physical activity self-efficacy) in the experimental group in the short term. The study results support similar findings from other studies that used a theory-based education programme to increase self-efficacy in pregnant women $[20,21]$ and improve pregnancy outcomes [22].

Socioeconomic status is a profound and consistent predictor of health status at both the population and individual levels [23] and differences in socioeconomic status between the intervention and controls groups could have affected the results. However, we found no significant differences between the

Table 2 Comparison of mean scores on health locus of control (HLOC) and selfefficacy between the experimental and control groups of women pre- and postintervention

\begin{tabular}{lccc} 
Variable & $\begin{array}{c}\text { Experimental } \\
\text { group }(\boldsymbol{n}=\mathbf{1 0 9}) \\
\text { Mean score (SD) }\end{array}$ & $\begin{array}{c}\text { Control group } \\
(\boldsymbol{n}=\mathbf{1 0 1})\end{array}$ & $\begin{array}{c}\boldsymbol{P} \text {-value } \\
\text { Mean score (SD) }\end{array}$ \\
$\begin{array}{l}\text { Pre-intervention } \\
\text { Internal HLOC }\end{array}$ & $15.9(3.9)$ & $15.8(3.3)$ & 0.918 \\
External HLOC & $23.5(4.7)$ & $24.0(4.2)$ & 0.409 \\
Exercise self-efficacy & $3.5(8.6)$ & $3.5(8.9)$ & 0.577 \\
Post-intervention & & & \\
Internal HLOC & $22.3(3.5)$ & $15.9(3.3)$ & $<0.001$ \\
External HLOC & $23.2(4.2)$ & $23.1(4.8)$ & 0.890 \\
Exercise self-efficacy & $18.9(1.8)$ & $11.0(3.3)$ & $<0.001$ \\
\hline
\end{tabular}

$S D=$ standard deviation.

groups in any of variables studied: education level, employment or self-rated economic status [24].

The significant changes in internality of the women in the experimental group add to existing evidence that individuals' beliefs can be modified. Individuals who believe their health is less dependent on influential others (high internal HLOC) are associated with a preference for information and health decision-making including weight loss [25], whereas low internal HLOC is associated with individuals taking health risks, including a continuous high cortisol stress response [26]. Our findings are therefore consistent with several studies reporting that individuals with an internal HLOC are more likely to avoid poor diet and physical inactivity at the preconception period and during pregnancy [27] and perceive a more positive birth experience [28]. On the other hand, women with an external HLOC orientation have been found to have significantly longer labour than those with an internal HLOC [29]. Therefore an important part of our study design was to recruit women before they become pregnant for the first time.

When interpreting the study findings, it is important to consider the 


\begin{tabular}{|c|c|c|c|c|c|}
\hline \multirow[t]{2}{*}{ Variable } & \multirow{2}{*}{$\begin{array}{c}\text { Experimental group } \\
\text { Change in mean score (SD) }\end{array}$} & \multirow{2}{*}{$\begin{array}{c}\text { Control group } \\
\text { Change in mean score (SD) }\end{array}$} & \multicolumn{3}{|c|}{ Statistics } \\
\hline & & & $t$-value & df & $P$-value \\
\hline Internal HLOC & $6.3(5.5)$ & $0.1(0.5)$ & 4.94 & 107 & $<0.001$ \\
\hline External HLOC & $0.7(2.6)$ & $0.3(1.3)$ & -3.094 & 102 & 0.003 \\
\hline Exercise self-efficacy & $10.3(4.1)$ & $2.1(5.4)$ & -25.917 & 107 & $<0.001$ \\
\hline
\end{tabular}

$S D=$ standard deviation; $d f=$ degrees offreedom .

limitations of the study. Although the sample and study design was appropriate for generalization to other women, it was not sufficiently diverse to make generalizations. Our sample targeted healthy married women intending to become pregnant within 1 year, which resulted in the recruitment of a highly motivated sample that may affect the generalizability of our findings. Additionally, a considerable proportion of the study subjects were highly educated, predominantly unemployed, women, which may also limit the generalizability of our results. We suggest that this type ofinvestigation should be replicated in a more diverse sample.
Nevertheless, the study intervention had a positive effect on the internal HLOC and self-efficacy of the study women. We believe that the current study adds to existing knowledge about the positive outcomes of health promotion interventions, in the form of a short-term lifestyle education focusing on physical exercise in women at the pre-pregnancy period. Despite some limitations, we believe that our results have practical implications for empowering women to adopt healthy lifestyles in the domain of physical exercise.

Considering the beneficial outcomes, investing in health promotion programmes that focus on the psychological determinants of healthy lifestyles of individuals (HLOC and selfefficacy) should be a high public health priority for improving the health of the entire population. The study findings could form a basis for future national health education policy and strategy in the Islamic Republic of Iran.

\section{Acknowledgements}

This research was supported by a grant from the World Health Organization EM/07/022893, and I.D. RPC 07/40 (TSA O7/04). In addition, we would like to thank all the women who participated in the study.

\section{References}

1. De Weerd S et al. Preconception nutritional intake and lifestyle factors: first results of an explorative study. European journal of obstetrics and gynecology and reproductive biology, 2003, 111:167-72.

2. Johnson BD et al. The relationship of demographic factors, locus of control and self-efficacy to successful nursing home adjustment. Gerontologist, 1998, 38(2):209-16.

3. Sasagawa $\mathrm{M}$ et al. Positive correlation between the use of complementary and alternative medicine and internal health locus of control. EXPLORE: the journal of science and healing, 2008, 4(1):38-41.

4. Hassanzadeh R et al. Relationship between health locus of control and health behaviors. Iranian journal of psychiatry and clinical psychology, 2006, 12:277-81.

5. Leong $\mathrm{J}$ et al. Adherence to health recommendations after a cardiac rehabilitation programme in post-myocardial infarction patients: the role of health beliefs, locus of control and psychological status. Clinical effectiveness in nursing, 2004, 8:26-38.

6. Lee L et al. The role of self-efficacy in older people's decisions to initiate and maintain regular walking as exercise: findings from a qualitative study. Preventive medicine, 2007, 45:62-5.

7. Roach J et al. Using self-efficacy to predict weight loss among young adults. Journal of the American Dietetic Association, 2004, 103(10):1357-59
8. Cross MJ et al. Patient self-efficacy and health locus of control: relationships with health status and arthritis-related expenditure. Rheumatology, 2006, 45(1):92-6.

9. Karimzadeh Shirazy K. To design a theory based health education program to improve calcium intake in women with osteoporosis [PhD dissertation] Department of Health Education, Tarbiat Modaress University, Tehran, Islamic Republic of Iran, 2004.

10. Fliess JL. The design and analysis of clinical experiments. New York, John Wiley and Sons, 1999.

11. Polit DF, Beck CT. Nursing research: principles and methods, 7th ed. Philadelphia, Lippincott Williams and Wilkins, 2003.

12. Haji Kazemy E et al. Investigating effect of premarital health counseling on females' awareness towards breast and cervical cancer. Quarterly Iran journal of nursing, 2006, 19(45):76-85.

13. Wallston BS et al. Development and validation of the health locus of control (HLC) scale. Journal of consulting and clinical psychology, 1976, 44:580-5.

14. Salehi L et al. Association of religious beliefs and locus of control with mental health in university students. Journal of Ghazvin Medical Sciences University, 2007, 11(1):23-9.

15. Moshki $\mathrm{M}$ et al. Assessing validity and reliability of multidimentional health locus of control in Iranian students. Scientific research journal of Ofogh Danesh, 2006, 2(12):33-41. 
16. Schwarzer R, Renner B. Health-specific self-efficacy scales. Berlin, Freie Universität Berlin, 2006 (http://userpage.fu-berlin. de/ health/healself.pdf, accessed 23 November 2009).

17. Lesan S. Effect of health education on Iranian firemen's coping self efficacy [PhD dissertation]. Tarbiat Moddares University, Tehran, Islamic Republic of Iran, 2004.

18. Bastani $\mathrm{F}$ et al. The effect of relaxation training based on self-efficacy on mental health of pregnant women. Journal of andisheh va raftar, 2006, 12(2):109-17.

19. Freda MC. Perinatal patient education: a practical guide with education handouts for patients. Philadelphia, Lippincott Williams and Wilkins, 2002.

20. Bastani $\mathrm{F}$ et al. A randomized controlled trial of the effect of applied relaxation training on reducing anxiety and perceived stress in pregnant women. American journal of midwifery and women's health, 2005, 50(4):36-40.

21. Bastani F et al. Effect of health education based on self-efficacy in reducing anxiety and perceived stress in pregnant women. Journal of andisheh va raftar, 2006, 3(45):23-30.

22. Bastani F et al. Does applied relaxation training reduce adverse pregnancy outcomes? A randomized controlled trial. American journal of perinatal and neonatal nursing, 2006, 20(2):138-46.
23. Adler NE et al. Socioeconomic status and health: the challenge of the gradient. American psychologist, 1994, 49(1):15-24.

24. Wiles R. Patients' perceptions of their heart attack and recovery: the influence of epidemiological "evidence" and personal experience. Social science and medicine, 1998, 46(11):1477-86.

25. Hashimoto $\mathrm{H}$ et al. The influence of locus of control on preferences for information and decision making. Patient education and counselling, 2004, 55:236-40.

26. Pruessner JC et al. Self-esteem, locus of control, hippocampal volume, and cortisol regulation in young and old adulthood. Neurolmage, 2005, 28:815-26.

27. Green JM, Coupland A, Kitzenger S. Expectations, experiences and psychological outcomes of childbirth: a prospective study of 825 women. Birth, 1990, 17:15-24.

28. Lavender T et al. A prospective study of women's views of factors contributing to a positive birth experience. Midwifery, 1999, 15:40-6.

29. Scott-Palmer J et al. Pain during childbirth and menstruation: a study of locus of control. Journal of psychosomatic research, 1981, 25:151-5.

\section{Second Annual Meeting of the Global Diabetes Alliance (GDA 2), Cairo, Egypt, 26-29 October, 2010}

Cairo will host the second Global Diabetes Alliance Congress, a very special event whose goal is to unify protocols for epidemiological surveys and prevention and management of diabetes and its related disorders. This Congress will be dedicated to the presentation of updates on the diabetes epidemic in various parts of the world (including the Middle East and Africa) and workshops designed to initiate collaborative research projects among groups of investigators throughout the world. The programme can be accessed from the conference website at: http://conf.global-diabetes. org/index.htm 